\title{
DISCURSO DE ABERTURA DO 28․ CONGRESSO GEOLÓGICO INTERNACIONAL - WASHINGTON, USA - JULHO 1989
}

\author{
Umberto Giuseppe CORDANI
}

Caros Colegas, Senhores e Senhoras,

Por tradição, o Presidente da União Internacional de Ciências Geológıcas (UICG) despede-se de seu mandato na Cerimônia de Abertura do Congresso Geológico Internacional, relatando os eventos que marcaram as Geociências em seu período de atuação. Devido ao precoce falecimento de W.W. Hutchison, em 1987, encontro-me diante de vocês não para me despedir, visto que meu mandato atual estende-se até 1992. Desta forma, estaremos juntos de novo na Cerimônia de Encerramento deste Congresso, e, se tudo correr bem, a tradição será mantida por ocasião da Cerimônia Inaugural do 29․ Congresso, no Japão.

Permitam-me iniciar meu relato oferecendo, em primeiro lugar, meu tributo à memória de Bill Hutchison. Sua energia incansável, sua capacidade fantástica de induzir as pessoas a colaborar, seu otimismo e seu entusiasmo foram extremamente benéficos para o desenvolvimento de muitos projetos de cooperação internacional, no mundo inteiro. Sua vida foi integralmente dedicada à Geologia e à UICG, e para mim é um grande privilégio poder seguir sua trilha.

Devo também deixar meu tributo ao Canadá, que ofereceu à Geologia pessoas do calibre do Dr. Hutchison, do Dr. Harrison, primeiro presidente da UICG, e muitos outros colegas. Em particular, o Serviço Geológico Canadense merece reconhecimento pela sua generosidade em promover colaboração científica internacional - tanto através dos mandatos de Bill Hutchison como Secretário Geral e como Presidente da UICG, como na editoração de nossa tão bemsucedida revista Episodes, e também pelo suporte da União durante o difícil período de transição que se sucedeu ao falecimento do Dr. Hutchison. Eugen Seibold, Presidente em exercício no período anterior à minha eleição, eu mesmo, e a própria União, externamos nosso reconhecimento ao suporte recebido dos canadenses.

As Ciências Geológicas estiveram em grande atividade nos últimos cinco anos. Embora não tenham ocorrido revoluções científicas do porte da Tectônica de Placas dos anos 60, houve con- siderável progresso em vários campos, e procurarei apenas evidenciar alguns exemplos, com base nas excelentes sugestões recebidas por parte de amigos e colegas de todo o mundo.

A maior das comissões da UICG, a Comissão de Estratigrafia, tem trabalhado incansavelmente na definição de alguns marcos estratigráficos importantes, tais como os limites Pré-Cambriano/Cambriano, ou Cretáceo/Paleoceno. Neste último aspecto, ela colabora com a Comissão de Geologia Sedimentar Global, na correlação de eventos na escala maior, reconhecíveis em muitos lugares do globo no registro sedimentar. Vocês podem estar interessados em saber que, em certas fases do Cretáceo, as evidências geológicas demonstram que a temperatura da superfície da Terra esteve cerca de 10 graus centígrados mais elevada do que hoje em dia. Palmeiras cresciam em latitudes muito altas, demonstrando deste modo que nosso planeta pode atingir tais condições extremas sem recorrer ao tão falado "efeito estufa", provocado pela ação do homem, ao poluir a atmosfera.

Progressos significativos ocorreram na Planetologia Comparada, através da análise das imagens de radar trazidas pelas sondas espaciais soviéticas Venera 15 e 16 . Vênus parece ter mais semelhanças com a Terra do que qualquer outro corpo do sistema solar, e os processos que nele ocorrem hoje em dia podem assemelhar-se aos que ocorreram em nosso planeta nos tempos primitivos de sua evolução, no Arqueano, em termos de temperaturas do manto superior, comportamento litosférico, estilos tectônicos e processos de espessamento crustal. A Missão Magellan, lançada recentemente pelos Estados Unidos, deverá produzir imagens de radar de alta resolução, além de dados altimétricos e gravimétricos, o que permitirá um melhor conhecimento da dinâmica de Vênus, e, por comparação, da história geológica antiga da própria Terra.

A Paleontologia reviveu nos últimos anos, com o desenvolvimento considerável da Paleontologia Molecular. A cooperação entre bioquímicos e paleontólogos está produzindo resultados 
espetaculares na compreensão das relações filogenéticas entre espécies viventes e extintas, demonstrando por exemplo que o homem se encontra em verdade mais próximo dos grandes macacos do que se supunha.

A interpretação geológica de perfis sísmicos profundos apresentou grandes progressos, como no caso dos projetos COCORP (americano), ECORS (francês), LITHOPROBE (canadense), e outros. A cooperação entre geólogos e geofísicos permitiu a correlação de descontinuidades sísmicas observadas nos perfis com estruturas geológicas existentes na superfície, e a evidência resultante demonstrou-se crucial para o entendimento da origem e evolução dos cinturões dobrados. Estes são agora entendidos como terrenos flotantes, grandes fragmentos crustais, separados de suas raízes litosféricas por importantes zonas tectônicas. O Projeto das Geotransectas Globais, com ênfase em interpretações crustais na escala maior, é o produto mais visível, e de maior impacto do Programa Internacional da Litosfera.

A visão tridimensional da litosfera continental tem enorme potencial. Fatalmente, nas próximas décadas, a Geologia terá que reconhecer a necessidade de mapeamento tridimensional da subsuperfície, bem como a modelagem tridimensional de materiais rochosos, circulação de fluidos, reservatórios, etc. Os métodos e as ferramentas estão sendo desenvolvidos recentemente e o gerenciamento dos recursos de subsuperfície deverá tornar-se a preocupação mais importante das Geociências, no futuro.

Sondagens continentais, única via de acesso às profundidades da crosta terrestre, são também o único meio direto existente para calibrar a natureza dos refletores sísmicos profundos. A tecnologia envolvida em tais empreendimentos é complexa, mas um certo número de poços profundos está em andamento ou em fase de planejamento, com a liderança dos soviéticos.

Entre os avanços recentes da petrologia, pequenos cristais de diamantes inclusos em granadas de paragnaisses do Kazaquistão demonstram que carbono proveniente de matéria orgânica esteve presente no sedimento original, e este foi levado para profundidades, na litosfera, da ordem de pelo menos $130 \mathrm{~km}$.

Nos campos de pesquisa do meu próprio interesse, geoquímica isotópica, geocronologia e evolução crustal, foram feitos avanços significativos na tecnologia analítica, especialmente nos espectrômetros de massa, nas microssondas iônicas, e na datação de cristais isolados de zircão. Foram efetuadas também importantes descobertas; datações precisas identificaram os mais antigos materiais terrestres conhecidos: poucos grãos de zircão detrítico em metassedimentos da Austrália Ocidental, com idades aparentes da ordem de 4.300 milhões de anos. Isto sugere que material granítico teria existido em épocas bem antigas da história geológica da Terra. Além disso, pesquisas com os isótopos de neodímio evidenciaram que porções substanciais da crosta continental foram formadas no Arqueano. Por outro lado, no Proterozóico Médio, nas Américas do Norte e do Sul foi identificado um dos maiores eventos formadores de crosta juvenil já ocorrido. Ofiólitos com 1.900 milhões de anos foram descobertos na Escandinávia, no Canadá e na União Soviética, tudo isto demonstrando que processos de tectônica de placas similares aos de hoje estiveram em operação há longo tempo, provavelmente desde o Arqueano.

Permitam-me agora tecer considerações sobre nossa profissão. Geólogos profissionais, especialmente aqueles envolvidos com depósitos minerais e Geologia Econômica, foram seriamente afetados na última década por uma recessão mundial. Com exceção do ouro, a utilização de insumos minerais foi reduzida nos países industrializados. Os preços caíram, e as companhias mineiras reduziram as atividades e seus orçamentos de exploração, daí resultando desemprego e desapontamento geral. Tais efeitos foram mais drásticos nos países desenvolvidos, onde os sistemas forçam os produtores à competição aberta pelos mercados mundiais. No Terceiro Mundo, onde a produção mineral encontra-se mais controlada pelos governos, as atividades continuaram, pois a produção não poderia ser sustada, qualquer que fosse o preço dos metais. Mas os resultados foram uma superprodução, uma receita reduzida, e dificuldades econômicas conseqüentes. Presentemente, a situação de depressão parece atenuada, resultando numa exploração renovada para muitos materiais como níquel, cobre, zinco.

Como representante do Terceiro Mundo, quero destacar a importância da mineração, não apenas em termos econômicos, mas através do papel que os geólogos de exploração podem exercer no avanço da cooperação Norte-Sul, visto que esta cooperação tem o potencial de reverter a situação atual de grande desvantagem para os países em desenvolvimento. As nações desenvolvidas, com cerca de um quarto da população mundial, estão utilizando mais de $80 \%$ da riqueza mineral global, qualquer que seja a sua origem. Como corolário, o potencial mineral do Terceiro Mundo tem sido benéfico, essencialmente, apenas para as nações industrializadas.

Como geólogo, acredito que todos nós temos a grande responsabilidade de entender os fa- 
tores sociais e econômicos que controlam o desenvolvimento dos recursos minerais, e estimar os seus efeitos. É nosso dever identificar o equilíbrio apropriado, a divisão de responsabilidades entre os governos e os interesses empresariais, que melhor atendam às necessidades de todas as partes envolvidas, ao mesmo tempo que os materiais necessários são fornecidos às indústrias.

Finalmente, em meu papel de "vidente", aqui vão alguns comentários sobre o futuro de nossa profissão e de nossa ciência.

A Geologia está se tornando cada vez mais quantitativa, com a crescente aplicação de informática e modelagem aos processos geológicos que buscam descrever a natureza e a evolução de nosso planeta. Exemplos dessa tendência encontram-se em toda parte: análise de bacias por meio de computação, tomografia sísmica do interior da Terra, simulação numérica para exploração de petróleo e depósitos minerais, cartografia digital, sensoriamento remoto, estabelecimento de bancos de dados digitais, etc. etc.

A Geologia está assumindo a perspectiva global, da Terra-como-um-sistema. Algumas das principais iniciativas da própria UICG refletem esta tendência: o Programa de Geologia Sedimentar Global, o Projeto de Geotransectas Globais, o Mapa Mundial de Esforços do Programa Internacional da Litosfera, e os diversos programas inerentes ao ambiente.

Isto me traz ao que considero o papel mais importante a ser assumido pelas Ciências da Terra nas próximas décadas: contribuir, de modo holístico, e em cooperação com muitos outros ramos da ciência, para atingir o assim chamado " desenvolvimento autosustentável", tal como foi definido no relatório Bruntland às Nações Unidas, "Nosso Futuro Comum',

Deterioração ambiental e os problemas relacionados representam agora a maior preocupação mundial. Os desafios transcendem os limites das jurisdições nacionais, e as decisões políticas a respeito do gerenciamento dos recursos naturais e do planejamento do uso da terra apresentam-se cruciais. Desenvolvimento autosustentável condicionará uma demanda sem precedentes por informações, assessoria, aplicações tecnológicas, que somente um enfoque integrado poderá satisfazer. Em muitos países, a ênfase dos desafios está se deslocando de proteção ou restauração para planejamento e prevenção, à medida que as soluções possíveis para os problemas ambientais tornam-se mais e mais com- plexas, e dependentes de uma infinidade de setores - o primeiro e mais importante deles sendo o da Ciência.

Degradação dos solos, desertificação, deflorestação, chuva ácida, poluição de aqüíferos como o resultado de uso excessivo de fertilizantes e pesticidas, riscos tecnológicos em usinas nucleares ou grandes indústrias químicas, rejeitos de mineração, poluição terrestre e marinha por vazamentos de óleo - tudo demonstra que a Terra encontra-se em plena crise ambiental, muitos destes problemas relacionando-se com a população em crescimento contínuo, aproximando-se do ponto de saturação. As atividades humanas envolvem atualmente um fluxo anual de materiais terrestres da mesma ordem daquele produzido pela tectônica de placas.

Em adição aos problemas ambientais locais ou regionais, há também preocupação crescente sobre as possíveis mudanças no ecossistema terrestre global, que poderão ser de efeitos duradouros sobre a humanidade. E finalmente devem ser considerados os riscos naturais catastróficos, como terremotos, erupções vulcânicas, tufões, inundações, deslizes de terra etc., que tão freqüentemente causam morte e destruição.

As Geociências têm um papel fundamental a cumprir ao considerar todos estes problemas. Com efeito, o registro geológico das mudanças globais do passado fornece a referência para estabelecer a natureza e a significação das mudanças presentes e futuras. Além disso, o estudo da dinâmica da Terra sólida fornece a base para a redução dos riscos naturais catastróficos.

A UICG, com sua ênfase na colaboração internacional multidisciplinar, pode contribuir decisivamente, com participação relevante no programa do ICSU sobre Mudanças Globais, ou na Década Internacional para Redução dos Desastres Naturais, das Nações Unidas. Como geólogos, somos guardiães do planeta. Mobilizemo-nos, preenchendo os vazios existentes no conhecimento para enfrentar tais ameaças globais, pois isto é vital para a sobrevivência da Terra e da própria humanidade. Não nos intimidemos frente a políticos e planejadores. Comuniquemo-nos com eles, pois presentemente a Geologia não faz parte de sua cultura. Todos nós sabemos como a Geologia é importante para a sociedade: façamos com que os educadores também compartilhem de nossos pontos de vista. É de nossa responsabilidade buscar reintroduzir as Ciências da Terra nos programas educacionais, de preferência nos níveis préuniversitários, onde os estudantes estão sendo apresentados ao ambiente em que todos vivemos, e aos sérios problemas que os afligem. 
Francis Bacon, no século 17, escreveu: ' $\mathrm{Pa}$ ra ser comandada, a natureza deve ser obedecida".

Senhoras e Senhores, vivemos num mundo de desafios, de muitas incertezas. Temos uma grande responsabilidade para com as gerações futuras, e devemos manter a fé em nossa capa- cidade, permanecendo organizados, para alcançar nossas metas comuns. Façamos uso crescente do imenso potencial da cooperação internacional. Comecemos agora, neste Congresso, a responder aos sinais que a natureza nos envia. Obedeçamo-la, para conduzi-la.

Desejo a todos proveitosas discussões científicas, e um Congresso de grande sucesso.

Endereço do autor:

- Umberto Giuseppe Cordani - Universidade de São Paulo - Instituto de Geociências - CP 20899 01498 - São Paulo (Brasil). 